\title{
Quran Courses Application
}

\author{
Asmaa Munshi \\ College of Computer Science and Engineering, Cybersecurity, University of Jeddah, \\ Jeddah, Saudi Arabia
}

Received: 06 July 2019; Accepted: 10 August 2019; Published: 08 November 2019

\begin{abstract}
The Quran courses application helps to manage and organize the Quran courses in the two holy mosques by displaying details of the Quran courses department, course times, registering possibilities, teachers' names and the capacity of every course. Furthermre, it allows the user to enroll on available courses depending on their age and gender by creating an account containing their personal information, such as name, age, gender, phone number and email.

The goal of this application is to display the courses that are in the two holy mosques and facilitate the enrollment process. The application permits communication between teachers and students, and targets those students who want to enroll in specific courses and the teachers who teach those particular courses. This application will be implemented using the same Android Studio programme that is employed in programming the Android applications and MySQL which manage the database. The Quran courses application utilizes usability testing to test the performance of an application and ensure it is usable and useful. This means that the basics function of the application meet the user's expectations and requirements in an easy and flexible manner without any breakdowns or technical malfunctions. It also means that any problems that users encounter can be identified and resolved. The overall results of the usability testing indicate that users and teachers are happy to use the Quran courses application. . The expected results of this application are that it will save time and effort for all students.
\end{abstract}

Index Terms: Quran courses, holy mosques, register, Usability testing

(C) 2019 Published by MECS Publisher. Selection and/or peer review under responsibility of the Research Association of Mode rn Education and Computer Science

* Corresponding author.

E-mail address: 


\section{Introduction}

Quran courses take place at the Makkah mosques and Medina mosques to provide effective instruction in the Quran for all ages, providing understanding of the meaning, background and other benefits of the Quran. It also aims to improve participants' reading of the Quran with Tajweed, which is essential to a better understanding in Quranic learning. Another potential benefit is that it would enable students to follow their course with greater time efficiency and to obtain an enhanced learning experience. The objective of this research is to develop a better environment for Quran courses by providing a firm foundation for the development and facilitation of Learning and communication between teachers and students [7].

Quran courses began with the Prophet and were dispersed thereafter, spreading throughout different regions such as Yathrib and Kufa and the most famous cities where the Quran was read and interpreted. A scientific approach to this study was established and continued through academic seminars and scientific institutes where the Holy Quran was taught, right up to the present day.

Our objective is to develop a system of education relating to the Quran which encompasses ongoing evaluation and review. The system is aimed at the next generation of learners and thus we are developing mobile applications to enable anybody to sign up for the Quran courses from all around the world and to have access to a chat facility which will permit them to communicate directly with their teachers [7].

This paper aims to describe the application that allows all people to access the list of available courses and many other features needed by anybody interested in Quran courses. The implementation of the application will be focused on people who interested in the Quran courses in the two holy mosques and all cities within the Kingdom of Saudi Arabia.

\section{Problem with Definition}

The idea for the application came from General Presidency for the Affairs of the Two Holy Mosques. Since currently there exists no mobile application for the Quran courses in the two holy mosques, which means that announcements for such courses are both rare and not widely known [3]. In addition, it is hoped that the application will change traditional concepts not only concerning knowing about Quran courses in the two holy mosques but also for enrolling in these courses. Thus, the application will facilitate enrolment in the courses from different cities, solve the problem of contact with teachers and make it possible to see the results of any course.

\section{Objectives}

The goal is to develop a mobile application for Quran courses in the two holy mosques that is flexible, convenient and able to function in any place where an internet connection is available. The most significant objectives of this project include:

1. Making this application available to all who wish to know about or enroll in Quran courses in the two holy mosques from everywhere in the world.

2. Displaying course information to users, including course dates and teacher names.

3. Allowing the user to select any courses they want to enroll in it, such as the correction of recitation, memorization and revision courses.

4. Facilitating user registration in the application through the providing of personal information such as name, age, gender, email, and password.Literature Review.

\section{Literature Review}




\subsection{Halagat omhat almoamneen [2014].}

Students in Jeddah who want to study and review the Qur'an can sign up themselves in the mosque of omhat almoamneen courses following a basic sign-up in the mosque. The application (omhat almoamneen) programme Qaaaf management Quran courses permits parents to communicate with their children's teachers and the course administrators and thereby to monitor their children's behaviour and grades. The initial sign-up method is done by the programme administrators who request student data the student such as full name, phone number and age. After this process is completed all students are provided with a password and ID to enable parents to monitor their children's performance [2].

\subsection{Agency of General Presidency for the Affairs of Al-Masjid Al-Nabawi Web site in Saudi Arabia [2014].}

It is intended that the website will offer users the option to sign up online to Quran courses by submitting their personal and academic information via the site. Users will also be able to obtain all the details concerning the Quran courses, including information about the departments involved, class times, and the age categories for each course [1].

\subsection{Read it correctly application [2013].}

This refers to an application applied in Jeddah and used since 2013 but with some specifications. It currently has additional specifications. The application used specifications relating to remote education which enable the users to sign up according to the name of the favorite teacher, the Quran reading which they want to access, and their gender because it is necessary to state whether the user is male or female. After the signing up process, the user can start using the application specifications [4].

\subsection{Qaaaf Mobile Application to serve the Quran [2014].}

Qaaaf is an upgraded version of Taj system, which provides innovative features to serve the Quran.Taj system which originated in Saudi Arabia at 1425 and has since undergone different developmental phases. Qaaaf was issued in 1436 and is now used in fourteen different countries with over 100,000 students. It provides a basis for Quran courses according to age and from which courses can be selected in accordance with levels, teachers and current availability [6]. Many mosques use qaaaf applications in their Quran courses, including the Amro bin Aljmoh School and the Othman bin Affan School in Alras in Saudi Arabia. Quran courses in prophet's and Makkah mosque was administered traditionally and it was required from the person to go to the mosque to be able to inquire about the courses and sign up, but now after the construction of this application has become easy to search and inquire and sign up in the courses from anywhere without come to the mosque.

\section{Design and Implementation of the Quran Courses Application}

The application is connected to an external database that we have established by using the WAMP Server. It is SQL based, so we have used the Android Studio programme to develop the application and its design. We have also used the Notepad++ programme to write the Java and PHP codes.The Quran courses application helps to manage and organize the Quran courses in the two holy mosques and possesses the ability to work at any place where an internet connection is available. Even if users have never enrolled on a course, the application allows them visitor access through which they can:

- Select one of two holy mosques (Makkah, Almadinah) 
- Check the gender section (Men, women, Children)

- Search for information about Quran Course

- Select a course (correction of recitation, memorization and revision)

After that the user can enroll in any available courses, depending upon their age and gender, by creating an account containing personal information such as name, age, gender, phone number and email. The application Content (Home, Advertising, Quran, Contact us, About us, Sharing, My Profile, Exit) is shown in fig. 1

Content (Home, Advertising, Quran, Contact us, About us, Sharing, My Profile, Exit) is shown in fig. 1
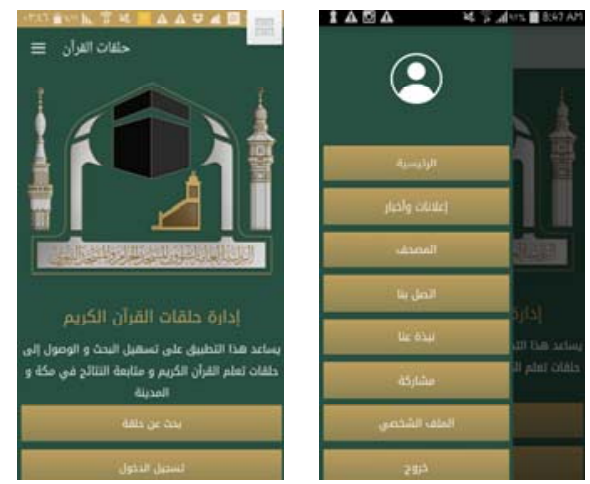

Fig. 1. Application Content

- Your Destination: this page displays only the Two Holy Mosquesa Mecca and al-medina so users should select one of them to register.

- Gender: This page displays information relating to the user's gender.

- Age categories: This page displays which courses available in the Two Holy Mosques in accordance with users' ages. There are three categories.

- Course Style: This page displays the types of Quran courses. It especially concerns the Two Holy Mosques and the user can select more than one type of course.

- Course Time Choices: This page displays all information about available times so that the user can enroll in accordance.

- Available Courses: This page displays all current available courses.

- Course information: This page displays all information about available courses.

- Sign in page: This page allows the user to sign in to the site after signing up.

- Sign up page: this page requires the user to submit certain relevant information in order to sign up.

- My profile: this page contains the user's schedule regarding enrolled courses, grades, contact options for the teacher, personal information and schedule modifications.

- Contact us: this page provides different ways to contact us

- About us: this page displays who built the application, what the application is doing and its objectives

\section{Usability Test Results}

\subsection{Participants and Study Design}


We recruited fifteen people to participate in the testing process, comprising two administrators, three teachers and ten Students. These users were linked to Quran course in mosques in Jeddah, and they had backgrounds in android systems. Specifically, the study group consisted of one male and one female administrator, three male teachers and six male and four female students. The aggregate participant age was fifteen years old and above. Quran courses usability testing was conducted on more than three Samsung mobiles. Test dates start on Monday 10th April 2017 and ended on Thursday 13th April 2017.

\subsection{Criteria Applied to Measure Usability}

When writing about website usability, [5] describes usability as a "...quality attribute that assesses how easy user interfaces are to utilize". Five principles were used to measure usability, as shown in Table 1. below. These criteria were applied to all functions included on our application and were tested by administration staff, teachers and students.

Table 1. Criteria Applied to Measure Usability, Based on Nielsen's (2003) Theory

\begin{tabular}{|c|c|c|c|c|c|}
\hline Measure & $\begin{array}{l}\text { Strongly } \\
\text { Agree }\end{array}$ & Agree & Disagree & $\begin{array}{l}\text { Strongly } \\
\text { Disagree }\end{array}$ & $\begin{array}{l}\text { No } \\
\text { Opinion }\end{array}$ \\
\hline \multicolumn{6}{|c|}{$\begin{array}{l}\text { Learnability: How easy is it for users to accomplish basic tasks when they } \\
\text { encounter the system design for the first time? }\end{array}$} \\
\hline \multicolumn{6}{|c|}{$\begin{array}{l}\text { Efficiency: Once users become familiar with the system design, how } \\
\text { quickly can they perform the required tasks? }\end{array}$} \\
\hline \multicolumn{6}{|c|}{$\begin{array}{l}\text { Memorability: When users return to the system having been inactive for a } \\
\text { period of time, how easily can they re-establish proficiency? }\end{array}$} \\
\hline \multicolumn{6}{|c|}{$\begin{array}{l}\text { Errors: How many errors do users make, how significant are these errors, } \\
\text { and how easily can they recover from the errors? }\end{array}$} \\
\hline Satisfaction: Is the design user-friendly? & & & & & \\
\hline
\end{tabular}

\subsection{Analysis of the Pre-Test Questionnaire Results}

A pre-test questionnaire was distributed to participants in order to ensure that they met the required skills and possessed the appropriate qualities to complete the test and capture the user feedback in relation to every task included on the application. In addition, participants were asked to identify the difficulties they facedduring completion of each task, while users were also required to complete the pre-test questionnaire after each task on the test.

\section{- Students' Questionnaire}

The ten students who used the Quran courses application were invited to complete students' questionnaire, the results of which are presented in Fig 2 to 9 below. 2 Admin, 3 Teachers, 10 Students. These users are from Quran course in some mosques of Jeddah and they have background about android system participated in this testing, there were 1 male and 1 female administration, 3 male teachers and 6 male and 4 female students. The aggregate number of participants was aged from fifteen years old and above. 
_ Task 1: Signing in

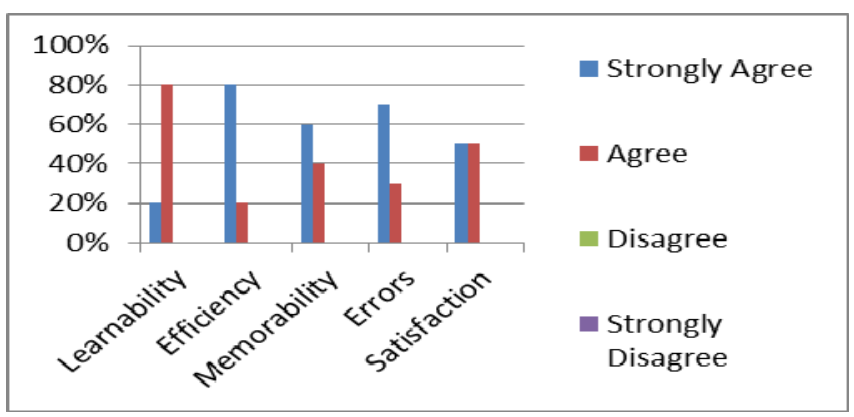

Fig 2. Analyze "Task 1" pretest result

- Task 2: Account creation

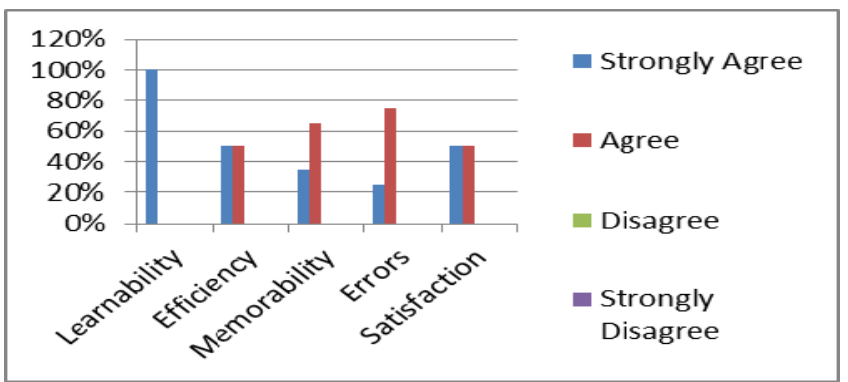

Fig 3. Analyze "Task 2" pretest result

— Task 3: Changing password

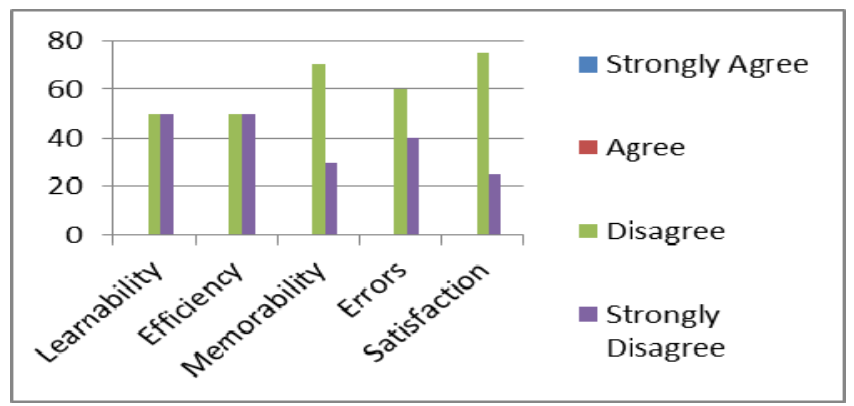

Fig 4. Analyze "Task 3" pre-test result 
— Task 4: Signing out

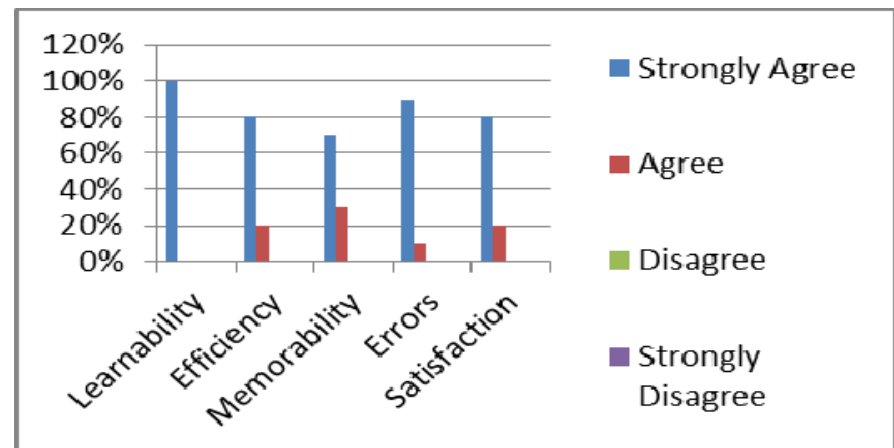

Fig. 5 Analyze "Task4" pre-test result

— Task 5: Searching for Quran courses

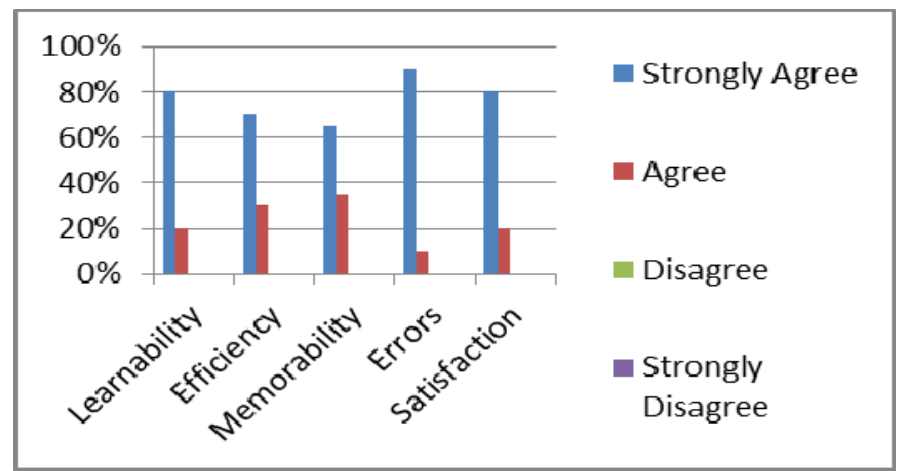

Fig. 6 Analyze "Task 5" pretest result

- Task 6: Viewing information about courses

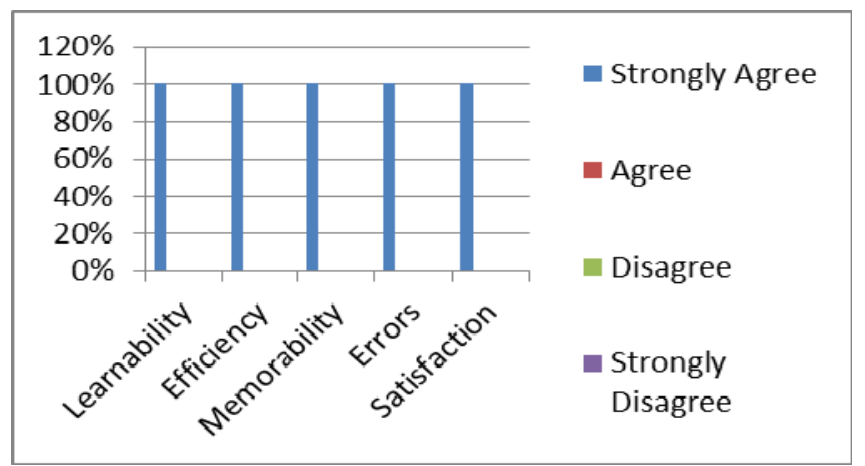

Fig. 7 Analyze "Task 6" pre-test result 
- Task 7: Course enrollment

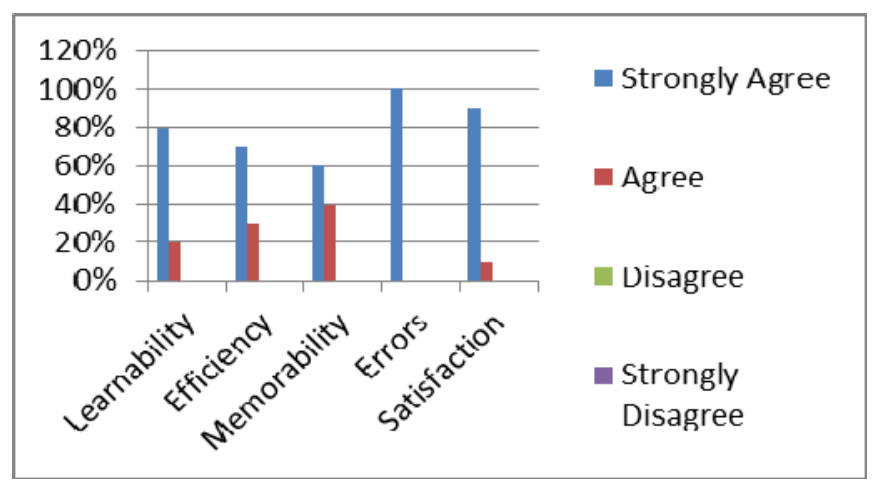

Fig. 8 Analyze "Task7" pre-test result

_ Task 8: Cancelling course enrollment

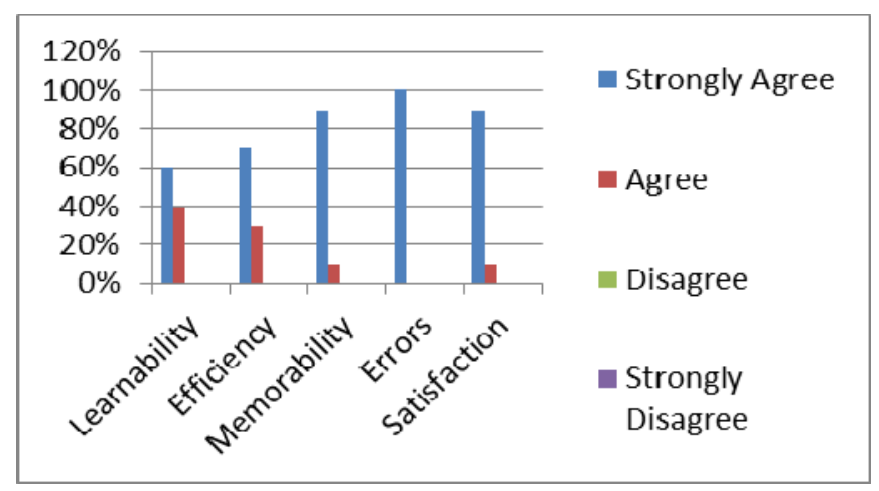

Fig. 9 Analyze "Task 8" pre-test result

\subsection{Problems and Recommendations as obtained from the Pre-test Questionnaire}

This section explores the problems and recommendations emerging from the pre-test questionnaire, as illustrated in Table 2 below.

Table 2. Problems And Recommendations

\begin{tabular}{|c|c|c|}
\hline Frequency & Description & Suggestions and Recommendations \\
\hline Task3: Change password: 6 of 10 students & $\begin{array}{r}\text { Students unable to change their password } \\
\text { because the edit button fails to work }\end{array}$ & $\begin{array}{r}\text { Ensure modifications are made to the edit } \\
\text { button }\end{array}$ \\
\hline
\end{tabular}

\subsection{Analysis of the Results of the Post-test Questionnaire}


Feedback obtained from the pre-test questionnaires specifically recommends that Tasks 3 be updated and improved, as proposed by both administrators and registered users respectively (see Fig. 10 below).

- Task 3: Change password

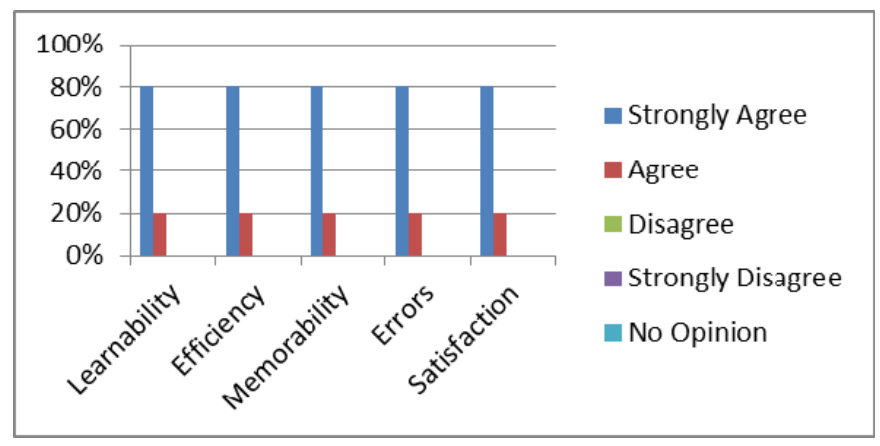

Fig. 10 Analyze Change Password Task, post- test results

\section{Conclusion \& future Work}

Launching this application will provide a perfect solution for those who wish to enroll in the Quran courses in the Two Holy Mosques. Furthermore, it will save the unnecessary time and time which is typically wasted through the traditional registration process.

The implementation of the application focuses on people who are interested in following Quran courses at the two holy mosques and all the cities of the Kingdom of Saudi Arabia. The mobile application will be structured so as to allow all people to access the application and to provide them with a list of available courses and many other features required by anybody interested in Quran courses. This application will help those interested in Quran courses in many ways, including:

- Enabling enrollment on the course to be done remotely without the need for direct attendance.

- Allowing teachers to evaluate all students enrolled on the course.

- Facilitating contact between the student and teacher through text or sound messages.

- Permitting students to see the results of each course on which they enrolled through the application.

- Adding news and advertisements related to the two Holy Mosques.

We hope to find in the future is that our application will be actualized for open utilize and everybody can get the advantage of it.

1. We can put a map for the two holy mosques to help the students to find Quran courses quickly.

2. We can add other languages with the Arabic language.

3. We can add spoken Quran for a large number of readers.

4. We can add Supplications Morning and Evening.

5. We can develop an app in IOS systems to Apple Store. 


\title{
Acknowledgements
}

We would like to thank Hend Alghamdi, Sameera Alshehri, Abrar Alnfeai, Asmaa Al-Qahtani, Abrar Alzahrani, and Asma Shati, who are students at the Faculty of Computing and Information Technology, Information Systems Department at King Abdul Aziz University for their support and assistance in this research

\section{References}

[1]Islamhouse, [Online] Available at: https://islamhouse.com/en/source/156098// . [Accessed 2008]. 2008. [2]IT, m., Omhat Almomeneen. [Online] Available at: http://appsto.re/sa/AvPm4.i [Accessed 12 October 2016]. 2014.

[3]J. S. Lisa, Technosigny, Community and Public Policy. Berlin: s.n. Monique, . M., 2015. Practices in Designing a Scholarly Journal and Its Style Guide [online]. 2002.

[4]Khayrokm, Otlooha Sah. [Online] Available at: http://appsto.re/sa/qqWMM.i [Accessed 9 October 2016]. 2013.

[5]NIELSEN, Human Computer Interaction Web Usability. [Online] Available at: https://www.nngroup. com /articles/ten-usability-heuristics/ [Accessed 2017]. 2003.

[6]Rateemah, [Online] Available at: <http://www.qaaaf.org/forum/postl.aspx?FrmId=28\&amp;ThdId=12677 $\& \mathrm{a}>.2015$

[7]S. Emily, Getting Back To The 3 Rs: Rigor, Relevance And Relationships. 2005.

\section{Author's Profile}

\begin{abstract}
Asmaa Munshi is an Assistance professor of Information Systems at Faculty of Computing and Information Technology at King Abdulaziz University. She has obtained her Ph.D. in Information System from Curtin University, Australia. She is currently serving as a head of Cybersecurity Department, University of Jeddah, and Jeddah, Saudi Arabia. Her research interest includes: Educational Technology, E-learning, Information Security and Data Integrity.
\end{abstract}

How to cite this paper: Asmaa Munshi," Quran Courses Application ", International Journal of Education and Management Engineering(IJEME), Vol.9, No.6, pp.1-10, 2019.DOI: 10.5815/ijeme.2019.06.01 